\title{
EFEITO DA ADIÇÃO DE CLORETOS DE ZINCO E MAGNÉSIO NOS PRODUTOS DA PIRÓLISE ANALÍTICA DE SORGO SACARINO
}

\author{
I. F. CUNHA ${ }^{1}$, W. S. CARVALHO ${ }^{1}$ e C. H. ATAÍDE ${ }^{1}$ \\ ${ }^{1}$ Universidade Federal de Uberlândia, Faculdade de Engenharia Química \\ E-mail para contato: chataide@ufu.br
}

\begin{abstract}
RESUMO - Devido às mudanças climáticas e à escassez de matéria prima fóssil, as energias alternativas se tornaram um assunto cada vez mais frequente e necessário. O sorgo sacarino é uma alternativa importante para a produção de biocombustíveis e insumos químicos. Este estudo teve como objetivo avaliar a influência da adição de dois cloretos inorgânicos $\left(\mathrm{ZnCl}_{2}\right.$ e $\left.\mathrm{MgCl}_{2} \cdot 6 \mathrm{H}_{2} \mathrm{O}\right)$ na composição dos produtos da pirólise analítica (Py-GC/MS) do bagaço de sorgo sacarino. Os principais compostos detectados nos cromatogramas da pirólise analítica foram: ácido acético, furfural, 5-Hidroximetilfurfural, 2,3dihidrobenzofurano, limoneno, isopreno e clorometano. O elevado teor de furfural obtido indica que a adição dos dois cloretos, pode ser uma alternativa promissora para a produção desse valioso insumo químico a partir da pirólise de bagaço de sorgo sacarino.
\end{abstract}

\section{INTRODUÇÃO}

A geração de efluentes gasosos nocivos ao meio ambiente e à saúde humana tem crescido muito nos últimos anos devido à queima de combustíveis fósseis. Uma alternativa para minimizar esses problemas é a utilização da biomassa; matéria residual de processos industriais e agrícolas, abundante e por isso de baixo custo. O sorgo sacarino, quinto cereal em importância no mundo depois do arroz, milho, trigo e cevada, é uma fonte muito atraente para produção de biomassa. O sorgo cresce rapidamente, apresenta cultura totalmente mecanizável (plantio por sementes, tratos culturais e colheita), utiliza menos água e fertilizante, alcança picos de açúcar em diferentes épocas do ano e possui alta produtividade de biomassa verde, entre 60 e 80t.ha ${ }^{-1}$ (Linton et al., 2011). Outra alternativa que vem sendo bastante estudada é a conversão dessa biomassa em bio-óleo, através de um processo conhecido como pirólise rápida, no qual materiais orgânicos são aquecidos a aproximadamente $500^{\circ} \mathrm{C}$.

A pirólise pode ser definida como a degradação térmica de um material orgânico na ausência parcial ou total de um agente oxidante (Bridgwater et al., 2000). A pirólise rápida tem como principais características curtos tempos de aquecimento das partículas e de residência dos vapores que se formam no interior do reator. Altas taxas de aquecimento, elevados coeficientes de transferência de calor e massa e manutenção cuidadosa da temperatura de reação, são fundamentais para alcançar os tempos curtos mencionados anteriormente. A principal vantagem da pirólise rápida, em comparação aos outros processos 
de conversão termoquímica da biomassa, é a produção de um derivado líquido (denominado de bio-óleo) que pode ser armazenado e transportado.

O principal objetivo no processo de pirólise é a obtenção de produtos com densidade energética mais alta e melhores propriedades do que aquelas da biomassa original. $\mathrm{Na}$ pirólise, os polímeros lignocelulósicos (hemicelulose, celulose e lignina) são submetidos a clivagem térmica para produzir diferentes componentes químicos que rapidamente vaporizam-se e, após condensação tem-se o bio-óleo. Outro produto da pirólise é um resíduo orgânico sólido chamado de "char" com algumas aplicações, como adubo e também a fabricação de filtros industriais. O bio-óleo é geralmente um combustível altamente oxigenado, ácido e corrosivo para os metais comuns, além de ser química e termicamente instável. Algumas técnicas para promover o melhoramento do bio-óleo são geralmente empregadas, como a adição de sais inorgânicos à biomassa para favorecer a formação de alguns compostos específicos ou menos oxigenados (Eom et al. 2012).

A cromatografia gasosa acoplada a espectrometria de massas, ou pirólise analítica, é uma técnica que permite a identificação dos principais compostos gerados nas reações pirolíticas e também o estudo da influência de variáveis como temperatura, distribuição de tamanho da amostra, taxa de aquecimento e uso de catalisadores na composição e concentração dos produtos gerados nas reações (Lu et al., 2011). A compreensão a respeito do comportamento dos materiais lignocelulósicos sob várias condições operacionais de pirólise é fundamental para se analisar a viabilidade do uso de bio-combustíveis ou produtos químicos produzidos a partir de diversas biomassas.

Considerando os aspectos abordados anteriormente, o foco maior deste estudo foi avaliar a influência da adição de dois cloretos inorgânicos $\left(\mathrm{ZnCl}_{2}\right.$ e $\left.\mathrm{MgCl}_{2} \cdot 6 \mathrm{H}_{2} \mathrm{O}\right)$ na composição dos produtos da pirólise analítica do bagaço de sorgo sacarino. Além disso, para um melhor entendimento da cinética de decomposição térmica desta promissora biomassa, também foram realizadas análises termogravimétricas, dos cloretos, da biomassa pura e também do bagaço impregnado com os sais.

\section{MATERIAIS E MÉTODOS}

\subsection{Material}

Nos testes foi utilizado um híbrido de sorgo sacarino desenvolvido pela Monsanto. Os colmos do sorgo foram cortados, esmagados em um moinho de rolos manual para a retirada da maioria do caldo, secos em estufa durante 24 horas e triturados em um moinho de facas. $\mathrm{O}$ bagaço utilizado, tanto nas análises termogravimétricas quanto na pirólise analítica, foi a fração passante pela peneira de 100mesh.

\subsection{Adição de Cloretos à Biomassa}

$\mathrm{Na}$ preparação das amostras impregnadas com os sais inorgânicos considerou-se a umidade inicial da biomassa. Para o cálculo do teor de umidade, o material foi mantido em estufa a $60^{\circ} \mathrm{C}$, tendo sido adotada esta temperatura baixa de secagem para evitar a volatilização de componentes da biomassa diferentes da água. $\mathrm{O}$ valor de umidade encontrado foi de $6,1 \pm 0,7 \%$, em base seca. Os cloretos de zinco (anidro P.A. Sigma Aldrich) e de 
magnésio (hexahidratado Sigma Aldrich) foram adicionados â biomassa nas concentrações mássicas de 5, 10 e 20\% (tendo sido descontada a quantidade de água no cloreto de magnésio), concentrações similares as utilizadas por Lu et al. (2011) empregando uma biomassa diferente.

Para adicionar os cloretos inorgânicos à biomassa, a respectiva quantidade de sal foi pesada em um béquer e a ela foram adicionados $50 \mathrm{~mL}$ de água destilada e deionizada a $70^{\circ} \mathrm{C}$. A solução gerada foi transferida para um béquer com a quantidade de biomassa calculada. Durante o processo de adição das soluções de sal foi realizada a mistura constante com agitador magnético para assegurar uma distribuição uniforme. Os béqueres com biomassa, sal inorgânico e água foram mantidos em estufa à $40^{\circ} \mathrm{C}$ durante $24 \mathrm{~h}$, posteriormente $60^{\circ} \mathrm{C}$ durante $24 \mathrm{~h}$ e $105^{\circ} \mathrm{C}$ durante $2 \mathrm{~h}$ para evaporação lenta da água. A evaporação lenta da umidade da amostra foi adotada para reduzir eventuais problemas de degradação da biomassa e arraste dos cloretos durante a etapa de secagem.

\subsection{Pirólise Analítica}

A pirólise rápida do bagaço de sorgo sacarino, tanto puro quanto impregnado com sais, foi realizada em um micro pirolisador CDS 5200. Uma pequena quantidade $(\mu \mathrm{g})$ da amostra foi inserida em um tubo capilar de quartzo, juntamente com lã de vidro. O gás inerte empregado foi Hélio (pureza 99.999). A taxa de aquecimento utilizada nas análises foi de $20^{\circ} \mathrm{C} / \mathrm{ms}$. As temperaturas adotadas para a pirólise foram de $450^{\circ} \mathrm{C}$ e $550^{\circ} \mathrm{C}$, temperaturas de reação usualmente utilizadas na pirólise de biomassa. Após atingir a temperatura final, a resistência do pirolisador permaneceu aquecida por 10 segundos. Todas as análises foram realizadas ao menos três vezes para garantir a reprodutibilidade dos resultados.

Os produtos de pirólise obtidos foram analisados por cromatografia gasosa e espectrometria de massas (GC/MS QP 2010 Plus da Shimadzu). A coluna Rtx-Wax com 30m de comprimento, $0,25 \mathrm{~mm}$ de diâmetro e $0,5 \mu \mathrm{m}$ de espessura do filme foi utilizada para a separação dos componentes presentes nos vapores. O processamento de dados foi realizado com a biblioteca de compostos NIST Versão 05. Apenas os compostos com índice de similaridade maior que $80 \%$ foram registrados, seguindo procedimento similar ao adotado em trabalhos anteriores (Cardoso, 2013).

\section{RESULTADOS E DISCUSSÕES}

\subsection{Pirólise Analítica de Sorgo Sacarino Impregnado com Sais}

Os principais compostos detectados nos cromatogramas da pirólise analítica, tanto do bagaço puro quanto do impregnado, foram ácido acético, furfural, 5-Hidroximetilfurfural, 2,3dihidrobenzofurano e limoneno. $\mathrm{O}$ aumento da temperatura de $450^{\circ} \mathrm{C}$ para $550^{\circ} \mathrm{C}$ levou à formação de isopreno. Esses compostos orgânicos são produtos químicos valiosos, especialmente o furfural, amplamente usado como solvente ou reagente orgânico para a produção de medicamentos, resinas, aditivos alimentares, aditivos para combustíveis e outros produtos químicos. 
Efeito da adição de $\mathrm{ZnCl}_{2}$ na distribuição de produtos: A Figura 1 apresenta o efeito da adição de $\mathrm{ZnCl}_{2}$ à biomassa na composição dos principais produtos oriundos da pirólise analítica de sorgo sacarino a $450^{\circ} \mathrm{C}$ e $550^{\circ} \mathrm{C}$.

Figura 1 - Efeito da adição de $\mathrm{ZnCl}_{2}$ na composição dos principais produtos a $450^{\circ} \mathrm{C}$ (A) e $550^{\circ} \mathrm{C}$ (B) $(\mathrm{CM}$ - Clorometano; IP - Isopreno; LM - Limoneno; AA - Ácido acético; FF - Furfural; 5-HMF - 5-Hidroximetilfurfural; 2,3-DBF - 2,3-Dihidrobenzofurano).
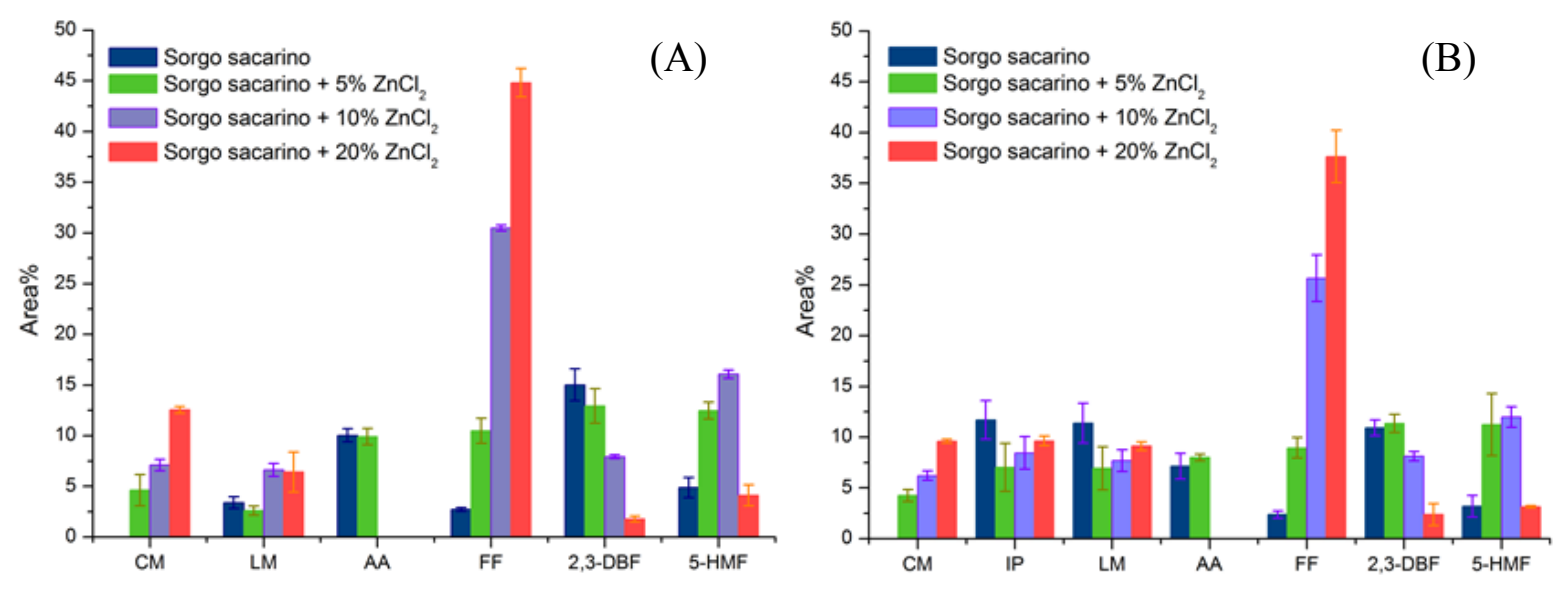

De acordo com a Figura 1, houve um aumento significativo na formação de furfural com o aumento da concentração de $\mathrm{ZnCl}_{2}$ tanto a $450^{\circ} \mathrm{C}$ (A) quanto a $550^{\circ} \mathrm{C}$ (B). Entretanto, observa-se um decréscimo nas porcentagens de área deste composto nos testes conduzidos na maior temperatura. $\mathrm{Na}$ pirólise analítica realizada com adição de $20 \%$ de $\mathrm{ZnCl}_{2}$ a $450^{\circ} \mathrm{C}$, o conteúdo máximo de furfural foi de aproximadamente $45 \%$ enquanto que a $550^{\circ} \mathrm{C}$ esse valor foi de aproximadamente $37 \%$. Esses valores indicam que a adição de $\mathrm{ZnCl}_{2}$ pode ser uma via promissora para a produção de furfural a partir da pirólise de bagaço de sorgo sacarino.

A impregnação de $\mathrm{ZnCl}_{2}$ pode reduzir a temperatura durante a decomposição completa da biomassa, inibindo a desvolatilização da lignina, bem como a cisão do anel da holocelulose. Enquanto isso, é promovida de forma significativa a despolimerização e desidratação da holocelulose para formação do furfural (Lu et al., 2011).O furfural é derivado de monômeros, tais como anidro-xilopiranose, levoglucosano e levoglucosenona (Shen et al., 2010). O aumento de monômeros pode ser justificado pela despolimerização de anidrooligossacarídeos. Por conseguinte, um aumento no rendimento de furfural implica numa diminuição no rendimento de anidro-oligossacarídeos.

Nota-se também na Figura 1 que houve a formação de clorometano com a adição do cloreto de zinco. Estudos anteriores demonstraram que o uso de $\mathrm{ZnCl}_{2}$ na pirólise causa a emissão de compostos clorados orgânicos voláteis (VOC) que podem ser encontrados tanto no gás quanto no bio-óleo.

Ainda na Figura 1, observa-se uma diminuição no conteúdo de 2,3-dihidrobenzofurano com o aumento da concentração de cloreto de zinco em ambas as temperaturas, enquanto a porcentagem de área do 5-hidroximetilfurfural aumentou com o aumento da concentração de $\mathrm{ZnCl}_{2}$. O rendimento máximo de 2,3-DHF foi alcançado nos ensaios com $10 \%$ de sal impregnado. O ácido acético não foi detectado nos testes com $10 \%$ e $20 \%$ de cloreto de zinco. 
Os demais compostos destacados na Figura 1 não apresentaram mudanças significativas com a adição do $\mathrm{ZnCl}_{2}$.

Efeito da adição de $\mathrm{MgCl}_{2}$ na distribuição de produtos: A Figura 2 apresenta o efeito da adição de $\mathrm{MgCl}_{2}$ à biomassa na composição dos principais produtos oriundos da pirólise analítica de sorgo sacarino a $450^{\circ} \mathrm{C}$ e $550^{\circ} \mathrm{C}$, respectivamente.

Figura 2 - Efeito da adição de $\mathrm{MgCl}_{2}$ na composição dos principais produtos a $450^{\circ} \mathrm{C}$ (A) e $550^{\circ} \mathrm{C}$ (B) (CM - Clorometano; IP - Isopreno; LM - Limoneno; AA - Ácido acético; FF - Furfural; 5-HMF - 5-Hidroximetilfurfural; 2,3-DBF - 2,3-Dihidrobenzofurano).
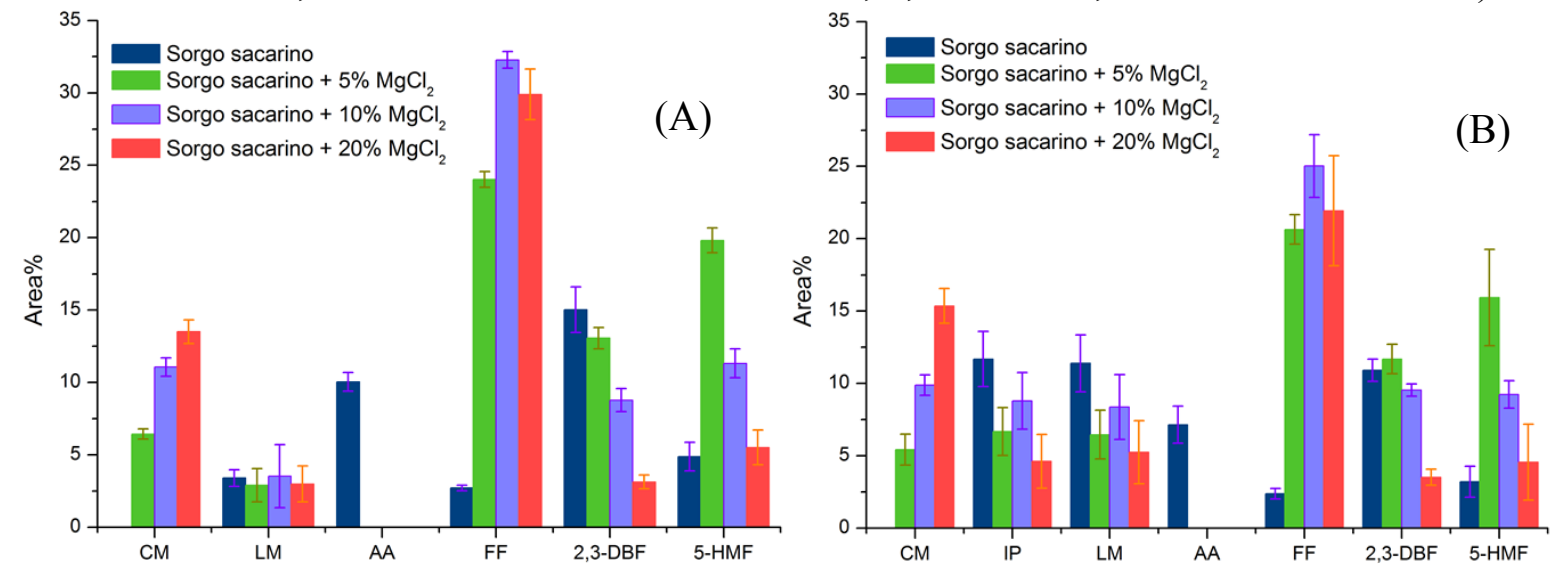

Assim como ocorreu com o cloreto de zinco, a adição de $\mathrm{MgCl}_{2}$ também alterou a composição dos principais componentes identificados na pirólise analítica em ambas as temperaturas (Figura 2). Houve um grande aumento no teor de furfural com o aumento da concentração, mas diferentemente do que ocorreu com o $\mathrm{ZnCl}_{2}$, a porcentagem de área máxima identificada (cerca de 33\%) ocorreu nos testes com $10 \%$ de cloreto de magnésio. Observou-se uma ligeira queda no teor de furfural quando a concentração de sal aumentou de 10 para $20 \%$. Uma queda similar na porcentagem de área de furfural foi observada nos testes a $550^{\circ} \mathrm{C}$. Estes resultados indicam que a adição de $\mathrm{MgCl}_{2}$ também pode ser uma alternativa para a produção de furfural a partir da pirólise de bagaço de sorgo sacarino, embora com uma seletividade menor do que aquela atingida nos testes com $\mathrm{ZnCl}_{2}$.

Segundo Liu et al. (2014), a adição de $\mathrm{MgCl}_{2}$ altera significativamente os mecanismos de reação da pirólise rápida de celulose a $325^{\circ} \mathrm{C}$. Enquanto a pirólise de celulose pura ocorre predominantemente através da despolimerização para libertar anidro-açúcares, na pirólise da celulose impregnada com $\mathrm{MgCl}_{2}$ predominam reações de reticulação, mesmo durante a fase de aquecimento, provavelmente devido ao enfraquecimento das ligações de hidrogênio.

Também observa-se na Figura 2 que houve uma diminuição no conteúdo de 2,3dihidrobenzofurano com o aumento da concentração de sal em ambas as temperaturas, tendência também observada nos testes com $\mathrm{ZnCl}_{2}$. Já a porcentagem de área do 5hidroximetilfurfural aumentou com a adição de $\mathrm{MgCl}_{2}$, mas diminuiu com o aumento da concentração de sal. O ácido acético não foi detectado nos testes com o bagaço impregnado. Novamente foi identificada a formação de clorometano, tanto a $450^{\circ} \mathrm{C}$, quanto a $550^{\circ} \mathrm{C}$. Os demais compostos destacados na Figura 2 não apresentaram mudanças significativas com a adição do $\mathrm{MgCl}_{2}$. 


\section{CONCLUSÕES}

As análises termogravimétricas indicam que a adição de sais inorgânicos modificou o perfil de degradação do bagaço de sorgo sacarino, havendo uma diminuição na temperatura de decomposição com o aumento da porcentagem de cloreto impregnado. Os principais compostos detectados nos cromatogramas da pirólise analítica foram: ácido acético, furfural, 5-Hidroximetilfurfural, 2,3-dihidrobenzofurano, limoneno, isopreno e clorometano. O elevado teor de furfural obtido indica que a adição, tanto de $\mathrm{ZnCl}_{2}$ quanto de $\mathrm{MgCl}_{2}$, pode ser uma via promissora para a produção desse valioso insumo a partir da pirólise de bagaço de sorgo sacarino.

\section{AGRADECIMETOS} pesquisa.

Os autores agradecem a CEMIG, ao CNPq, a Capes e a FAPEMIG pelo apoio a esta

\section{REFERENCIAS}

BRIDGWATER, et al. Fast pyrolysis processes for biomass, Renewable and Sustainable Energy Reviews, Vol. 4, pp. 1-73, 2000.

CARDOSO, C. R., Efeito da temperatura e da adição de sais inorgânicos na pirólise analítica de resíduo de tabaco. 2013. 124p. Tese (Doutorado em Engenharia Química) Universidade Federal de Uberlândia, 2013.

EOM, et al. Effect of essential inorganic metals on primary thermal degradation of lignocellulosic biomass. Bioresource Technology, v. 104, p. 687-694, 2012.

LINTON, J. A. et al. Economic feasibility of producing sweet sorghum as an ethanol feedstock in the southeastern United States. Biomass and Bioenergy, v. 35, n. 7, p. 30503057, 2011.

LIU, D. et al., 2014. Effect of $\mathrm{MgCl}_{2}$ loading on the evolution of reaction intermediates during cellulose fast pyrolysis at $325^{\circ} \mathrm{C}$. Proc. Combust. Inst.

$\mathrm{LU}, \mathrm{Q}$. et al. Selective fast pyrolysis of biomass impregnated with $\mathrm{ZnCl} 2$ to produce furfural: Analytical Py-GC/MS study. Journal of Analytical and Applied Pyrolysis, v. 90, n. 2, p. 204-212, 2011.

SHEN, D. K. et al. Study on the pyrolytic behaviour of xylan-based hemicellulose using TG-FTIR and Py-GC-FTIR. Journal of analytical and applied pyrolysis, v. 87, n. 2, p. 199 - 206, 2010. 